\title{
Pre-Service and In-Service Teachers' Views on Gamification
}

\author{
https://doi.org/10.3991/ijet.v17i03.26761

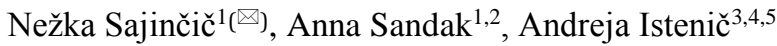 \\ ${ }^{1}$ InnoRenew CoE, Izola, Slovenia \\ ${ }^{2}$ Natural Sciences and Information Technologies, University of Primorska, Koper, Slovenia \\ ${ }^{3}$ Faculty of Education, University of Primorska, Koper, Slovenia \\ ${ }^{4}$ Faculty of Civil and Geodetic Engineering, University of Ljubljana, Ljubljana, Slovenia \\ ${ }^{5}$ Department of Psychology and Education, Kazan Federal University, Kazan, Russia \\ nezka.sajincic@innorenew.eu
}

\begin{abstract}
Despite the popularity of gamification among academics due to its propensity to promote student motivation, engagement, and behavioral change, its use in formal education is still limited. We reached out to educators at all levels to examine their experience, attitude, familiarity with gamified teaching, and their personality, to see if teachers' personal characteristics are related to the intention of implementing gamified teaching. 118 in-service and 102 pre-service teachers completed the BFI-S and the questionnaire developed for the study. Teachers predominantly assumed that gamification represents game-based learning, and more than half reported using some game elements in at least one of their lectures. While in general participants were welcoming towards gamified teaching, experienced teachers had a more positive attitude toward gamification compared to pre-service teachers. Attitude was a mediator between the intention to use and a presumption that gamification means using educational games, experience with gamification, and openness. In addition, past use significantly predicted intention to use even when accounting for attitude. Both in-service and pre-service teachers expressed a wish to learn more about gamification. The study identified another gap between theory and practice, showing a need for teachers to be informed more regularly about the latest pedagogical strategies and approaches.
\end{abstract}

Keywords - attitude, behavioral intention, educational games, experience, game mechanics, gamification, knowledge, openness, personality, teacher

\section{Introduction}

The staggering success of the gaming industry has left practitioners and researchers wondering if the engaging nature of game playing can be harnessed for more productive purposes, such as facilitating learning. As information-communication technology (ICT) has been blurring the line between formal, non-formal, and informal education, game-based learning and gamification have become interesting approaches to improve outcomes outside the traditional gaming context, such as students' motiva- 
tion, engagement, and performance. The number of publications on gamification in education has indeed been steadily growing in the last decade but focused mainly on its design principles and results [1], [2]. However, years of research on technology acceptance have shown the leading role of personal characteristics in predicting the adoption of pedagogical innovations [3], [4]. For this reason, this article focuses on a surprisingly overlooked subsection of gamification users - teachers. As students perceive their teachers to be their role models when introducing new approaches and ICT tools [5], we looked at educators from various levels and their characteristics, attitudes, and practices related to gamification use in education.

\subsection{Gamification in education}

Using games to support teaching and learning or game-based learning is not new as teachers have been trying to direct the intrinsically motivated and enjoyable experience of game playing to facilitate education-related outcomes. Gamification, on the other hand, is a similar but distinct concept [6], not including fully fledged games, but instead applying only game design elements in non-gaming contexts [7], like education, to make it more game-like. It can be used in digital and non-digital environments alike. The most commonly used game elements in education are points, challenges, badges, rankings or leaderboards, and stories [2], [8], [9], while others, like avatars, levels, and goods or prizes, seem to be used less often for learning purposes. Gamified learning seems to be suitable for various subject areas [9] on all educational levels [10] and demonstrates predominantly positive results, such as increased engagement, motivation, fun, academic achievement, effort, interest, participation, and more positive attitudes [2], [9], [11]-[13]. However, there are also studies reporting mixed results [8], indicating that the effectiveness of gamification may at least in part depend on personal characteristics.

\subsection{Attitude, familiarity, experience, and personality in relation with gamification in education}

Empirical studies demonstrating the key role personal determinants play in adopting pedagogical innovations have inspired research in the field of gamified learning as well, especially on attitude. Attitude represents the individual's favorable or unfavorable evaluation of a particular object [14] made up of three underlying components: emotional response (affect), beliefs about the object (cognition), and behavior [15]. Attitude seems to be one of the main predictors of behavioral intention related to the object in question [16]. For instance, multiple studies showed attitudes toward technology significantly predict teachers' intention to use said technology and also help explain the relationship between behavioral intentions and other constructs [3]. Knowledge or awareness is one such variable as it is an important predictor of behavior, either directly as familiarity with an object such as ICT tools makes it more likely to use it as part of instruction [17], or indirectly through forming more positive attitudes [18], [19]. 
Attitude has been recognized as an important variable in adopting gamification in education as well. Notably, studies have been focusing mainly on the students' point of view (e.g., [20]-[23]), neglecting the role of teachers as designers of instruction until recently. While there is a number of studies examining the attitude of teachers towards game-based learning (e.g., [24]-[26]), research on teacher attitudes towards gamified education without using games is less common, is usually explorative, and focuses on teachers from a singular educational level.

While some studies report in-service and pre-service teachers to be familiar with gamification [27], others reveal that the majority of teachers believe it means learning through educational games [28], [29]. However, despite having an unclear idea about what gamification entails, teachers reported using gamification elements like badges and leaderboards to increase students' motivation, performance, participation, and positive behavior [28]. Past experience with a specific technology or approach is relevant as it influences its' acceptance and intention to use it both for teaching practitioners and pre-service teachers [30], [31]. For instance, future teachers with experience using digital badges intend to use them in their future practice [32].

Most teacher candidates and teachers on different levels have a positive attitude towards gamification [29], [32]-[34] and believe it can be useful to improve student motivation, enjoyment, interest, and performance by developing several competencies, such as teamwork, self-regulated learning, critical thinking, oral communication, participation, and social skills, but they also think it can make classroom management harder [21], [29], [34]-[37].

Nevertheless, only a small fraction of teachers use gamification regularly [33]. Technical and management obstacles are highly cited barriers to utilizing gamification, but teacher characteristics emerged as a contributing factor as well. Among the latter, lack of sufficient knowledge on gamification and skills for its implementation, attitude, control, and risk avoidance emerged as personal variables relevant to acceptance intention [29], [38], [39].

In addition to an individual's attitude, personality is also one of the factors that can affect novelty or technology acceptance, especially openness to new experiences [40]. Openness is one of the five fundamental dimensions of personality (together with extraversion, neuroticism, conscientiousness, and agreeableness) that refers to a willingness to engage with novel and complex ideas, individuals, cultures, sensations, and all other experiences [41].

Recent research has shown that openness and extraversion indirectly affect attitudes and behavioral intention using technology in teaching [42] and teachers who were more open to ICT were more likely to perceive game-based learning as more valuable and use it in their practice [43]. Furthermore, openness, extraversion, and conscientiousness were shown to be connected with students' preferences and motivation in a gamified learning environment [44], [45].

\subsection{Purpose of the study and research hypotheses}

As designers of their curriculum and role models to their students [5], teachers represent a key part of the equation in introducing innovations in their instruction [3]. 
Despite the many benefits gamification brings in learning environments [9], [11], its use among teachers is still low [33], indicating yet another example of the disconnection between educational science and practice [46]. For this reason, the study aimed to explore the teachers' attitude towards gamification, their familiarity with it, experience using its' principles, and intention to use it in the future, together with the relationship between these factors and teachers' personalities. Due to the similarity between gamification and games, we were also interested in the association between gamification variables and the frequency of playing games in leisure time.

Previous research has shown that there may be some differences in how pre-service and in-service teachers form their attitude on technology use and its integration, which may be a consequence of the discrepancy in professional experience and knowledge that is required to incorporate technology into their practice [3], [47], [48]. Consequently, we also aimed to examine and compare the views of both teacher groups.

To the authors' best knowledge, this will be the first study to include educators from all levels and link several personal factors to the intention of future gamification use. Even though the purpose of the study is mainly explorative, based on the literature, we propose the following hypotheses:

- H1: Teachers do not distinguish between gamification and game-based learning.

- H2: Most of the participants have not used gamification in practice.

- H3: The most used game elements are points, challenges, badges, leaderboards, and stories.

- H4: There will be a significant difference between pre-service and in-service teachers' attitude, familiarity, and experience with gamification in education.

- H5: Experience and familiarity with gamification are directly associated with the intention of future use, but also indirectly with positive attitude as a mediator.

- H6: Openness to experience is directly and indirectly associated with the intention of future use through a positive attitude.

\section{Method}

\subsection{Participants}

A convenience sample of 220 subjects participated in the study ( $82 \%$ female); 102 subjects were undergraduate students from a Slovenian Faculty of Education $(98 \%$ being between 18 and 25 years old) and 118 subjects were in-service teachers $(88 \%$ between 26 and 55 years old), 103 of them from Slovenia and 15 from seven different countries (see [49]). Inclusion criteria were being a teacher or in training to become one, being at least 18 years old, and understanding English or Slovene (93\% of respondents filled the survey in Slovene). Before starting the survey, participants read an informed consent form with information about the study and their rights. Participation was voluntary and subjects did not receive any compensation. 


\section{$2.2 \quad$ Instruments}

The quantitative data were obtained with a survey that was designed for this study based on an extensive literature review. The instrument (see [49]) consists of six sections: a) demographic information and frequency of playing games, b) knowledge of gamification, c) actual use of gamification, d) attitudes towards gamification, e) the likelihood of future use of gamification, and f) personality (BFI-S). To ensure greater sensitivity and consistency, most items required the participants to rate their degree of agreement with the statements on a 7-point scale (1-Considerably disagree, 4Somewhere in between, 7-Considerably agree) [50].

In the first section, participants reported their gender, age group, citizenship, teaching experience, educational level and field [51], estimated weekly time spent playing games (on a 6-point scale from never to more than ten hours), and the platform they played the most games on in the past year.

To assess familiarity with gamification, the participants rated their agreement with two statements that were based on previous research [29]. The first, "I know the concept of gamification well," reported their self-assessment, while the second, "Using gamification in education means learning through games or the use of didactic, educational games," verified if they know enough to differentiate gamification from gamebased learning, a similar, but different, concept.

Then, a short description of gamification and its mechanics, followed by three examples of its use in education, were provided to ensure every participant had the same representation of the concept before they estimated how many times they used gamification in the past year (1-Zero times to 5-More than ten times) and which game mechanisms they have used.

The next section consisted of 32 statements about the teachers' attitude towards gamification use in education. The questions included affective, behavioral, and cognitive components of attitude and were developed based on previous literature [24][26], [29], [52]. Seventeen statements were worded inversely to lower respondents' confirmation bias and increase the scale's construct validity [53]. The reliability of the scale was high $(\alpha=.95)$ (see [54] for factor analysis of the instrument).

Next, the participants rated the probability of using gamification in their practice in the next year (1-Not at all likely, 4-Somewhere in between, 7-Definitely) and chose which gaming mechanisms they are most likely to use.

This was followed by the Short 15-item Big Five Inventory (BFI-S) [55] - a selfassessment questionnaire that measures five dimensions of personality.

Finally, there was an open-ended question that invited participants to provide comments, concerns, or experiences about using gamification in education and training.

The questionnaire was first developed and reviewed in Slovene and then translated to English. Two Slovene speakers with good command of English and the survey content contributed to the instrument's development. They first translated the survey from Slovene to English and then compared the two versions and checked for inconsistencies to ensure both instruments were adequate. 


\subsection{Procedure}

Data was collected in the academic years 2019/2020 and 2020/2021. Both versions of the survey were created with the 1 ka survey tool [56] and distributed via e-mail and Facebook by the snowball method. Some copies were also printed and distributed at the EDUvision 2019 conference from 28 to 30 November 2019 in Ljubljana, Slovenia. The average time to complete the online questionnaire was 11 minutes.

Data was analyzed using the open-source software $\mathrm{R}$ [57] and jamovi [58]. The total attitude score was obtained by averaging the 32 items (where some items were reverse coded). In addition to descriptive statistics, we calculated group differences and correlation coefficients. We also conducted a multiple mediation analysis by bootstrapping 5000 resampled data sets to elucidate the relationship between several independent variables $(X)$ and the intention of future gamification use (dependent variable $Y$ ) and see if it can be partly or wholly accounted for through attitude as a mediating variable $(M)$ (Figure 1; [59]). When applicable, we used non-parametric alternatives to $t$-tests and Pearson's correlation (Mann-Whitney U test, Spearman's correlation) and adjusted the significance threshold $(\alpha)$ with the Bonferroni correction $(\alpha / n)$ to control the increased risk of false positives when conducting multiple statistical tests [60].

Responses to the open-ended question were categorized by the first author. If comments included more than one theme, they were coded in multiple categories.

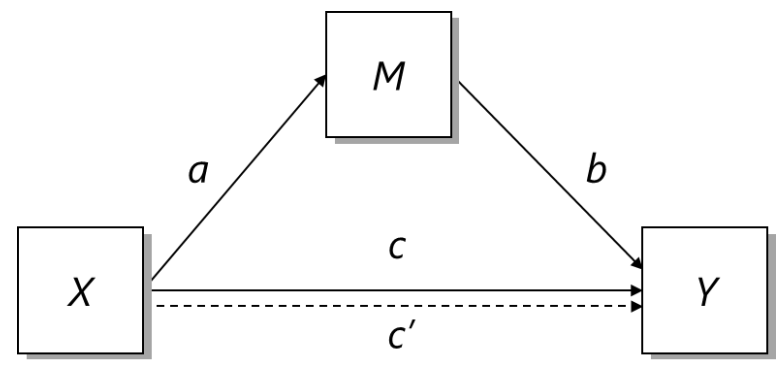

Fig. 1. Simple mediation model

\section{$3 \quad$ Results}

\subsection{Descriptive statistics}

Pre-service and in-service teachers were prudent in their self-reported familiarity with gamification, mainly disagreeing with the notion that they know the concept well $(M=2.90, S D=1.71, M d n=2, I Q R=2-4$; Figure 2a). This is consistent with the commonly expressed belief that gamification means learning through games $(M=4.65$, $S D=1.55, M d n=5, I Q R=4-6$; Figure 2b), implicating two things. First, most participants do not distinguish between gamification and game-based learning, and second, the following results must be interpreted with caution. While respondents were presented with a description and examples of gamification use afterward, we cannot be 
certain whether teachers had gamification or games in mind when filling the rest of the questionnaire.

I know the concept of gamification well.

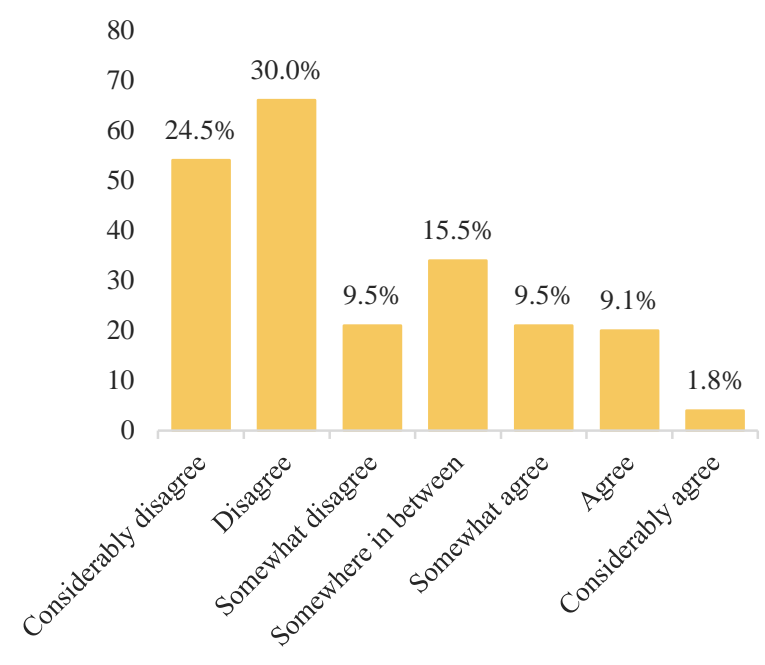

(a)

Using gamification in education means learning through games or the use of didactic, educational games.

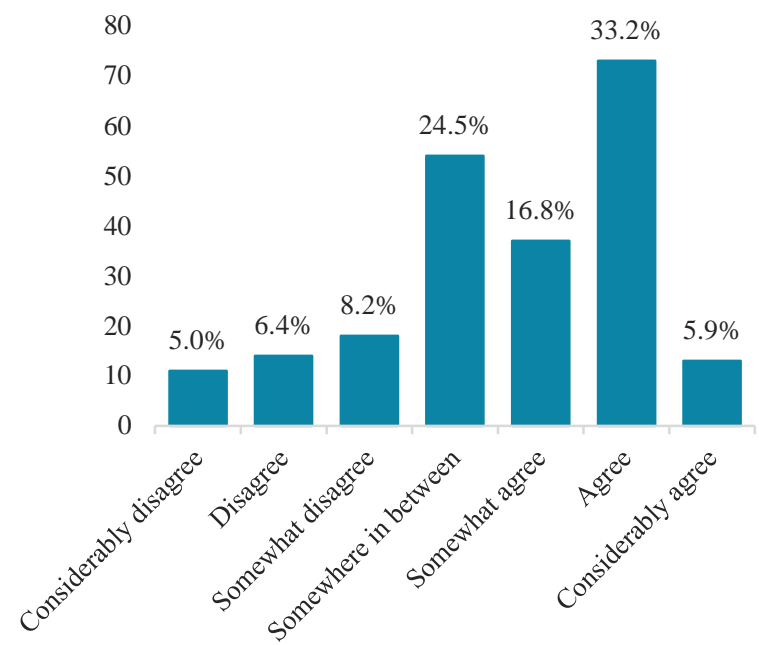

(b)

Fig. 2. Frequencies on a) self-reported and b) tested familiarity with gamification 
Forty-one percent of in-service teachers reported they have not used gamification in the past, while almost a third used its principles in six lectures or more in the last year. The most commonly used game mechanics, encompassing game rules guiding players actions, were points, challenges, and stories, while levels, avatars, and (virtual) goods were used the least; a similar pattern emerged when participants reported the mechanics they are most likely to use in the future (Figure 3). Even a quarter of students with no formal teaching experience reported having used a gamification principle at least once. There was a significant increase $(t(219)=-13.70, p<.001, d=-$ $0.92)$ from the number of reported game mechanics used in the past $\left(M_{\text {past }}=1.09\right.$, $\left.S D_{\text {past }}=1.59\right)$ to the number of game mechanics respondents believe they will probably use in the next year $\left(M_{\text {future }}=2.89, S D_{\text {future }}=1.86\right)$.

Most participants reported they never play games (81 or $37 \%$ ) or that they play less than one hour per week (69 or $31 \%$ ).

The overall attitude towards gamification was slightly positive $(M=4.95, S D=0.87$, $\min =1.75$, $\max =6.88$ ) with the highest scoring items being about wanting to know more about it $(M=5.44, S D=1.51)$ and wanting to use gamification to make learning more fun $(M=5.36, S D=1.47)$, interesting $(M=5.31, S D=1.45)$, to promote active participation $(M=5.30, S D=1.41)$, and to motivate students $(M=5.27, S D=1.34)$. Both groups agreed the least with item 22 that says they would refuse to implement gamification if students would suggest it $(M=2.34, S D=1.24)$ as well as item 7 , implying using gamification in education is a waste of time and resources $(M=2.45, S D=1.24)$.

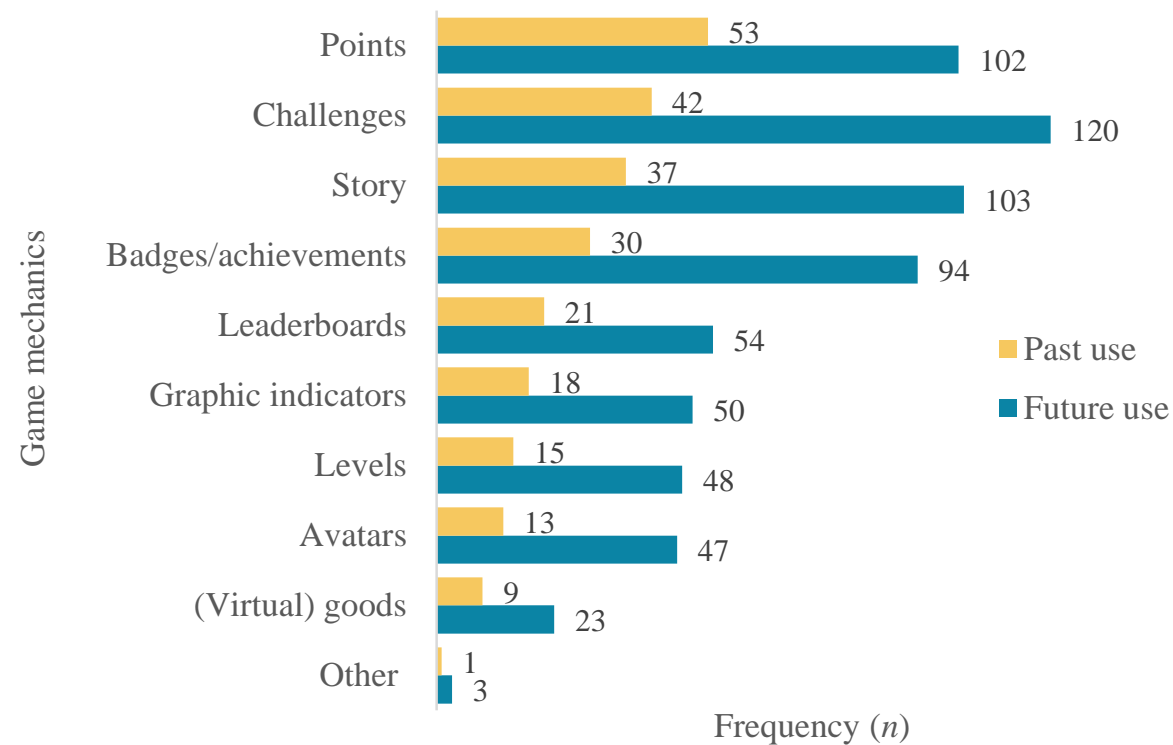

Fig. 3. Frequency of past and future use of game mechanics 


\subsection{Group differences}

Mann-Whitney U test was used to compare future and current teachers' differences in past use, knowledge, and intention to use gamification with a Bonferroni-adjusted $\alpha$ level of $0.013(0.05 / 4)$. There were significant differences in self-reported $(U=3104$, $p<.001, d=0.48)$ and tested $(U=4675.50, p=0.003, d=0.22)$ familiarity with gamification and past gamification use $(U=3503, p<0.001, d=0.42)$, while both groups were equally likely to use gamification in the future $(U=4986.50, p=0.026, d=0.17 ; M d n$ $\left.{ }_{p r e}=4, I Q R_{p r e}=3-5 ; M d n_{i n}=5, I Q R_{i n}=3-6\right)$, but only with the corrected $p$ value. Preservice teachers were less sure about what gamification is $\left(M d n_{\text {pre }}=2, I Q R_{\text {pre }}=1-2\right.$; $\left.M d n_{i n}=4, I Q R_{i n}=2-5\right)$ and more careful in their assumption that learning through games constitutes gamification $\left(M d n_{p r e}=4, I Q R_{p r e}=4-6 ; M d n_{i n}=5, I Q R_{i n}=4-6\right)$ compared to in-service teachers. Professionals, as expected, had more experience with using gamification principles in the past $\left(M d n_{\text {pre }}=1, I Q R_{\text {pre }}=1-1.75 ; M d n_{\text {in }}=2, I Q R_{\text {in }}=1\right.$ 4).

There were no significant differences based on gender, but in-service teachers from other countries reported significantly higher knowledge of gamification compared to Slovenian teachers $\left(U=323.50, p=<0.001, d=0.58 ; M d n_{s l o}=4, I Q R_{s l o}=2-5 ; M d n_{\text {oth }}=6\right.$, $\left.I Q R_{\text {oth }}=4.50-6\right)$. However, there was a big difference in group sizes $\left(N_{s l o}=103\right.$, $N_{\text {oth }}=15$ ), so these results should be interpreted with caution.

An independent samples t-test showed that differences in attitude towards gamification between pre- and in-service teachers were also significant $(t(218)=2.41$, $p=0.02, d=0.33)$, with teaching professionals $\left(M_{i n}=5.08, S D_{i n}=0.92\right)$ having a more positive view of gamification than students $\left(M_{p r e}=4.80, S D_{p r e}=0.77\right)$. Next, we explored potential differences in individual attitude items towards gamification (Table $1)$. Students were more worried gamification would encourage unrest $\left(M_{\text {pre }}=3.89\right.$, $\left.S D_{p r e}=1.29 ; \quad M_{i n}=3.10, \quad S D_{i n}=1.52\right)$, excessive social comparisons $\left(M_{p r e}=4.19\right.$, $\left.S D_{\text {pre }}=1.51 ; M_{i n}=3.27, S D_{i n}=1.57\right)$, and competitiveness in the classroom $\left(M_{\text {pre }}=4.35\right.$, $\left.S D_{\text {pre }}=1.40 ; M_{i n}=3.37, S D_{i n}=1.64\right)$, and would also have a greater feeling that gamification activities were only distracting students from the actual learning content $\left(M_{\text {pre }}=3.30, S D_{\text {pre }}=1.39 ; M_{i n}=2.64, S D_{i n}=1.31\right)$ with moderate effect sizes $(d=0.49$ $0.64)$.

Table 1. Differences between pre-service and in-service teachers on attitude items

\begin{tabular}{|l|c|c|c|}
\hline \multicolumn{1}{|c|}{ Item } & $\boldsymbol{t}$ & $\boldsymbol{p}$ & $\boldsymbol{d}$ \\
\hline $\begin{array}{l}\text { 1. Gamification encourages participation of all students, including those that } \\
\text { participate less frequently and have difficulty in doing so. }\end{array}$ & 0.09 & 0.93 & 0.01 \\
\hline $\begin{array}{l}\text { 2. Gamification of learning content and processes in the classroom is difficult to } \\
\text { implement. }\end{array}$ & -0.89 & 0.38 & -0.12 \\
\hline 3. I am worried that gamification would encourage unrest in the classroom. & 4.13 & $<.01$ & 0.56 \\
\hline $\begin{array}{l}\text { 4. I would implement gamification in learning activities to make learning more } \\
\text { fun for students. }\end{array}$ & 0.15 & 0.88 & 0.02 \\
\hline 5. Gamification promotes only superficial learning. & 2.16 & 0.03 & 0.29 \\
\hline 6. Using gamification in education would overwhelm me. & 0.62 & 0.54 & 0.08 \\
\hline 7. The use of gamification in education is a waste of time and resources. & 1.59 & 0.11 & 0.22 \\
\hline
\end{tabular}




\begin{tabular}{|c|c|c|c|}
\hline $\begin{array}{l}\text { 8. I would implement gamification in the learning activities so the students would } \\
\text { participate more actively during lessons. }\end{array}$ & 0.58 & 0.56 & 0.08 \\
\hline 9. Gamification is not an appropriate method for effective learning and teaching. & 1.89 & 0.06 & 0.26 \\
\hline 10. Gamification is suitable only for use at lower educational levels. & 0.79 & 0.43 & 0.11 \\
\hline 11. I am skeptical about the benefits of using gamification in education. & 1.98 & 0.05 & 0.27 \\
\hline $\begin{array}{l}\text { 12. If I would be implementing new pedagogical approaches or technologies, it } \\
\text { would not be gamification. }\end{array}$ & 0.77 & 0.44 & 0.10 \\
\hline $\begin{array}{l}\text { 13. I am worried gamification would encourage excessive social comparison with } \\
\text { students. }\end{array}$ & 4.39 & $<.01$ & 0.59 \\
\hline $\begin{array}{l}\text { 14. I would implement gamification to help students achieve better learning } \\
\text { outcomes. }\end{array}$ & 1.18 & 0.24 & 0.16 \\
\hline $\begin{array}{l}\text { *15. If I would implement gamification, I would have a feeling that it is only a } \\
\text { distraction from the learning content. }\end{array}$ & 3.62 & $<.01$ & 0.49 \\
\hline $\begin{array}{l}\text { 16. Gamification makes more sense in a digital/virtual environment than in a } \\
\text { classroom. }\end{array}$ & 2.01 & 0.05 & 0.27 \\
\hline $\begin{array}{l}\text { 17. I am worried gamification would excessively encourage competitiveness } \\
\text { between students. }\end{array}$ & 4.74 & $<.01$ & 0.64 \\
\hline $\begin{array}{l}\text { 18. Because of gaming mechanisms, students can } \\
\text { ronment and thus feel more competent in their lea }\end{array}$ & 2.24 & 0.03 & 0.30 \\
\hline $\begin{array}{l}\text { 19. I would implement gamification in learning activities so students } \\
\text { more choice during the course and feel more autonomous in their lea }\end{array}$ & 0.41 & 0.68 & 0.06 \\
\hline 20. I want to know more about the use of gamification in teaching. & 0.9 & 0.37 & 0.12 \\
\hline $\begin{array}{l}\text { 21. I would use gamification in my teaching so the learning content would be } \\
\text { more interesting to students. }\end{array}$ & 0.98 & 0.33 & 0.13 \\
\hline $\begin{array}{l}\text { 22. If students would suggest implementing gamification in the classroom, I } \\
\text { would refuse. }\end{array}$ & 1.22 & 0.22 & 0.17 \\
\hline $\begin{array}{l}\text { 23. I would implement gamification in learning activities to make students more } \\
\text { attentive to the learning content and materials. }\end{array}$ & 1.46 & 0.15 & 0.20 \\
\hline $\begin{array}{l}\text { 24. Gamification makes students put more effort into learning and learning activi- } \\
\text { ties. }\end{array}$ & 0.14 & 0.89 & 0.02 \\
\hline 25. Gamification is suitable for most of the learning material I teach. & 0.34 & 0.73 & 0.05 \\
\hline $\begin{array}{l}\text { 26. If I would use gamification, I would have a feeling I was wasting time for } \\
\text { teaching. }\end{array}$ & 1.13 & 0.26 & 0.15 \\
\hline 27. Gamification in education brings more disadvantages than benefits. & 1.84 & 0.07 & 0.25 \\
\hline $\begin{array}{l}\text { 28. With the help of gamification, students would understand the learning material } \\
\text { better. }\end{array}$ & 0.62 & 0.54 & 0.08 \\
\hline 29. I want to apply the principles of gamification in my teaching practice. & 1.04 & 0.30 & 0.14 \\
\hline $\begin{array}{l}\text { 30. I would implement gamification in learning activities to motivate students to } \\
\text { learn. }\end{array}$ & 1.35 & 0.18 & 0.18 \\
\hline 31. Students put more effort in group work because of gamification. & 0.32 & 0.75 & 0.04 \\
\hline 32. I think students would not be interested in gamification. & 2.97 & $<.01$ & 0.40 \\
\hline
\end{tabular}

Note. $d f=218$; significant differences with a Bonferroni-adjusted $\alpha$ level of $0.002(0.05 / 32)$ with an *.

\subsection{Correlations}

There were no significant correlations between gamification variables and experience variables (game playing, game platform, teaching experience, educational level, and field), with few exceptions. Teachers with more experience were slightly more 
familiar with gamification $\left(r_{\mathrm{s}}=.35, p=<.001\right)$ and had some more experience with using it in the past $\left(r_{\mathrm{s}}=.36, p=<.001\right)$, but only if students with no experience were included in the sample. Teachers at the lower level of elementary school were more likely to have used gamification in the past $\left(r_{\mathrm{s}}=.35, p<.001\right)$, while university professors and assistants reported slightly higher knowledge about gamification $\left(r_{\mathrm{s}}=.31\right.$, $p<.001)$.

As seen in Table 2, almost all gamification variables correlated between themselves, but these relationships were mostly weak. Teachers and students with previous experience with gamification use and with higher scores on both knowledge variables were more likely to have a positive attitude towards gamification and were more likely to use its' principles in the future. However, there was a strong connection between intention to use gamification and positive attitude towards it $\left(r_{\mathrm{s}}=.65, p=<.001\right)$ and a moderate one between likely future use and experience with using game mechanics in the past $\left(r_{\mathrm{s}}=.56, p=<.001\right)$. Surprisingly, self-assessed familiarity with gamification was not only linked with past use but also the incorrect assumption that gamification means learning through games. Even though participants were provided with information about gamification before responding to items about attitude and intention of future use, interpretation of results should be made with caution because we cannot be certain the participants had the same interpretation of the concept.

Table 2. Spearman's $r_{\mathrm{s}}$ correlations between gamification and personality variables

\begin{tabular}{|l|c|c|c|c|c|}
\hline & Knowledge & G as GBL & Past use & Attitude & Intention \\
\hline Knowledge & - & & & & \\
\hline G as GBL & $0.34^{*}$ & - & & & \\
\hline Past use & $0.27^{*}$ & 0.16 & - & & \\
\hline Attitude & $0.27^{*}$ & $0.34^{*}$ & $0.35^{*}$ & - & \\
\hline Intention & $0.25^{*}$ & $0.32^{*}$ & $0.56^{*}$ & $0.65^{*}$ & - \\
\hline Openness & 0.15 & 0.09 & 0.12 & $0.28^{*}$ & $0.19^{*}$ \\
\hline Consciousness & 0.07 & 0.07 & 0.09 & $0.21^{*}$ & 0.12 \\
\hline Extraversion & 0.03 & 0.05 & 0.17 & 0.12 & 0.18 \\
\hline Agreeableness & 0.00 & -0.04 & 0.00 & 0.22 & 0.08 \\
\hline Neuroticism & -0.12 & $-0.19^{*}$ & -0.07 & $-0.13^{*}$ & -0.09 \\
\hline
\end{tabular}

Note. Significant correlations with a Bonferroni-adjusted $\alpha$ level of $0.005(0.05 / 10)$ with an *, "G as GBL" stands for "gamification as game-based learning".

The big five personality dimensions were mostly uncorrelated or correlated weakly with gamification variables, with the strongest link being between attitude and openness $\left(r_{\mathrm{s}}=.28, p=<.001\right)$. Teachers that are more open reported a slightly higher chance of using game mechanics in the future $\left(r_{\mathrm{s}}=.19, p=.005\right)$, while people that are more conscious $\left(r_{\mathrm{s}}=.21, p=.002\right)$ and agreeable $\left(r_{\mathrm{s}}=.22, p=.001\right)$ were a bit more positive about gamification. 


\subsection{Mediation analysis}

Next, we tested whether attitude mediates the relationship between the knowledge variables, past gamification use, openness, and intention of future use (Figure 4).

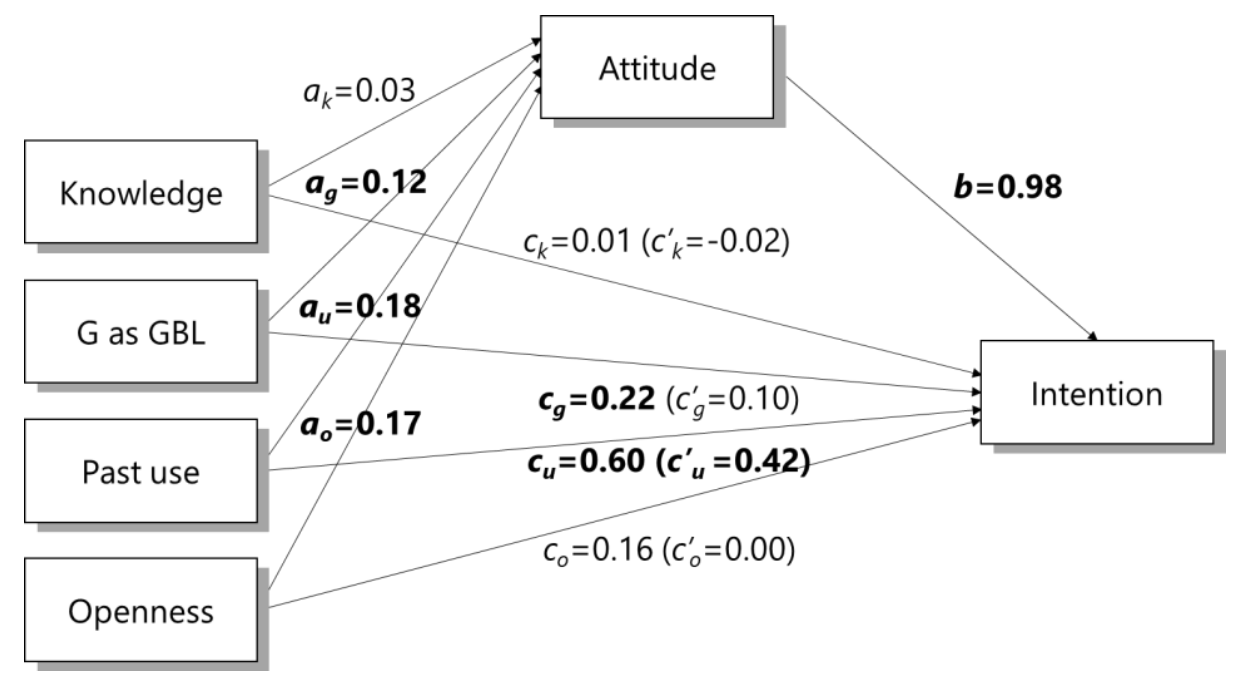

Fig. 4. The tested mediation model with unstandardized path coefficients (significant links at $\alpha=0.05$ in bold)

Attitude towards gamification has been shown to partly explain the relationship between three independent variables and the likelihood that teachers will use it in the future (Table 3). A significant indirect effect has been shown in the case of the false belief that gamification is learning through games as well as likelihood of future use $\left(a b_{s}=0.12,95 \% C I\right.$ [0.04-0.21], $\left.p=0.006\right)$, past gamification use $\left(a b_{u}=0.17,95 \% C I\right.$ [0.1-0.26], $p=<.001)$, and openness $\left(a b_{o}=0.17,95 \% C I\right.$ [0.04-0.30], $\left.p=0.013\right)$, but not in the case of self-assessed knowledge $\left(a b_{o}=0.03,95 \% C I\right.$ [-0.05-0.10], $\left.p=0.435\right)$. While the relationship between perceiving gamification as game-based learning and the inclination to use gamification in the future was significant, only the experience with gamification influenced the intent of future gamification use even when accounting for positive attitude towards it.

Table 3. Indirect, direct, and total effects of two knowledge variables, past use, and openness on intention to use gamification through attitude

\begin{tabular}{|c|c|c|c|c|c|c|c|}
\hline Type & Effect & Estimate & SE & $95 \% \mathrm{CI}$ & $\beta$ & $Z$ & $p$ \\
\hline \multicolumn{8}{|c|}{ Model summary for Knowledge } \\
\hline Indirect & Knowledge $\Rightarrow$ Attitude $\Rightarrow$ Intention & 0.03 & 0.04 & $-0.05-0.10$ & 0.03 & 0.78 & 0.44 \\
\hline Direct & Knowledge $\Rightarrow$ Intention & -0.02 & 0.05 & $-0.11-0.08$ & -0.02 & -0.38 & 0.71 \\
\hline Total effect & Knowledge $\Rightarrow$ Intention & 0.01 & 0.06 & $-0.1-0.12$ & 0.01 & 0.20 & 0.84 \\
\hline \multicolumn{8}{|c|}{ Model summary for Gamification as GBL } \\
\hline Indirect & G as GBL $\Rightarrow$ Attitude $\Rightarrow$ Intention & 0.12 & 0.04 & $0.04-0.21$ & 0.11 & 2.76 & $<.01$ \\
\hline
\end{tabular}


Paper-Pre-Service and In-Service Teachers' Views on Gamification

\begin{tabular}{|l|c|c|c|c|c|c|c|}
\hline Direct & G as GBL $\Rightarrow$ Intention & 0.10 & 0.06 & $-0.01-0.20$ & 0.09 & 1.76 & 0.08 \\
\hline Total effect & G as GBL $\Rightarrow$ Intention & 0.22 & 0.06 & $0.09-0.34$ & 0.20 & 3.49 & $<.01$ \\
\hline Model summary for Past use \\
\hline Indirect & Past use $\Rightarrow$ Attitude $\Rightarrow$ Intention & 0.17 & 0.04 & $0.1-0.26$ & 0.15 & 4.19 & $<.01$ \\
\hline Direct & Past use $\Rightarrow$ Intention & 0.42 & 0.06 & $0.31-0.54$ & 0.36 & 7.34 & $<.01$ \\
\hline Total effect & Past use $\Rightarrow$ Intention & 0.60 & 0.07 & $0.47-0.73$ & 0.51 & 8.98 & $<.01$ \\
\hline Model summary for Openness & \multicolumn{7}{|l|}{} \\
\hline Indirect & Openness $\Rightarrow$ Attitude $\Rightarrow$ Intention & 0.17 & 0.07 & $0.04-0.30$ & 0.10 & 2.48 & 0.01 \\
\hline Direct & Openness $\Rightarrow$ Intention & 0.00 & 0.08 & $-0.17-0.15$ & 0.00 & -0.05 & 0.96 \\
\hline Total effect & Openness $\Rightarrow$ Intention & 0.16 & 0.09 & $-0.02-0.34$ & 0.10 & 1.77 & 0.08 \\
\hline
\end{tabular}

Note. Percentile confidence interval is based on 5000 bootstrap samples.

\subsection{Open-ended responses}

Twenty-five participants responded to an open question inviting them to share their thoughts or experiences with gamification in education and training. Four answers were removed as they were comments about the survey, and the rest were categorized by their valence - nine were positive (e.g., "with its help we get faster learning results and such knowledge is more effective"), four were negative (e.g., "knowledge should be a value by itself"), and eight were neutral (e.g., "gamification has its place, but not everywhere and at any cost. Like everything, it needs good planning in a pedagogical context").

Comments were also scanned for recurring themes but were very individual, mostly made up of unique codes. The most common category was comprised of six respondents wishing for more information on the subject, one specifying they "would like to see practical examples without the use of computers." Several teachers pointed out the benefits of gamification, such as bringing something new and innovative to the classroom (three) and it being interesting for the students (two). A teacher shared this experience:

"... students who are more restrained reject it at the beginning, but when they see that it is interesting and instructive, it encourages and activates them /.../ and motivates them and they want to have more lectures like that."

Two participants believed gamification would not promote competitiveness but would allow the children to monitor their progress and teachers to tailor their lectures. Two teachers, however, remarked it is more suited to individual work than to larger groups like classrooms, expressing concerns about being able to cater to different interests and characteristics of children and having trouble with controlling younger students. Three teachers also voiced worries regarding implementation, citing considerable effort, time, and needing help. One participant commented they are not willing to put the time into gamifying their lesson on their own so they would use already existing content, while another shared a negative experience:

"I had used a gamification in one course. It was quite time-consuming, and I couldn't keep updates frequent. As at the same time I haven't seen clear improvement in students' knowledge and motivation, so I resigned." 


\section{Discussion}

Gamification is an innovative approach that can increase student motivation, engagement, fun, and performance [2], [9], [11]-[13] by applying game elements and concepts in non-game contexts such as education [7]. As well as other educational technologies and pedagogical novelties, however, gamification's success rate may be influenced not only by its qualities but also by the degree of acceptance by its users [3], [4]. Therefore, this study explored personal characteristics of in-service and preservice teachers related to the adoption of gamification in education, namely their attitude, experience, familiarity with it, and openness to new experiences.

Similar to previous studies, most teachers and teacher candidates were not particularly familiar with gamification and how to use it in education, predominantly believing it means learning through games [28], [29]. Working professionals and educators teaching at the university level were a bit more knowledgeable than pre-service teachers, mainly due to the differences in experience.

More than half of in-service teachers and a quarter of students reported using gamification at least once in the past year, but due to the inability to distinguish between using games and gamification, this result should be interpreted with caution. Teachers at the lower level of elementary school had the highest probability of using game elements in their teaching. The most frequently used game mechanics were points, challenges, stories, badges, and leaderboards, following the pattern found by recent meta-analyses [2], [8], [9].

Both in-service and pre-service teachers had a positive attitude towards gamification use in education, would implement it if their students suggested it, and perceived it as a valued investment of time and resources. Most participants wished to know more about the use of gamification in teaching and expressed they would use it to make learning more fun, interesting, and motivating for their students. However, there were some differences between participants with different levels of experience that mirrored previous studies on technology acceptance [3], [47], [48]. Compared to preservice teachers, in-service teachers were more positive about gamification in general, while pre-service teachers expressed more concerns, such as gamification being a distraction and encouraging unrest, excessive social comparisons, and competitiveness. Some teachers perceived difficulties in implementing gamification, such as accommodating too many different individuals and needing considerable effort, time, and help to do so.

Teachers that were more open, agreeable, and conscious had a slightly more positive attitude towards gamification use, while game playing was not related to using or having positive views about gamification. A favorable evaluation of gamification in education turned out to be the strongest predictor of intention to use gamification. Furthermore, we partly confirmed our predicted model as attitude mediated the relationship between tested familiarity with gamification, past use, and openness to experience and intention of future use, which matches findings of similar research on ICT adoption [17]-[19], [30]-[32], [42], [43]. Self-assessed knowledge of gamification did not predict future intention to use it in any way, and openness contributed only 
through a positive attitude, while other personality traits did not play a significant role.

There are some limitations to the study that decrease the generalizability of our findings. First, the positive relationship between the assumption that gamification includes educational games, favorable attitude, and greater likelihood of future use is another reminder that participants may have had the wrong perception of gamification when filling out the questionnaire. Although respondents read a description of gamification and game mechanics use in education before answering non-knowledge-related items, we are unsure whether the following responses concerned game-based learning or gamification. These results are a consequence of using a non-validated instrument. While the attitude questionnaire has been shown to be highly reliable and comprised of two factors (namely, positive and negative attitudes towards gamification [54]), content validity is still questionable and should be verified in follow-up research. Next, due to performing a larger number of comparisons, we used a Bonferroni correction to control for false positives [60]. However, this method is very conservative and increases the probability of type II error, meaning some significant associations may have been shown to be non-significant, which should be considered by future studies. Finally, a major limitation of the study is its sample; in addition to having a small numerus and including only 15 non-Slovenian citizens, using a nonprobabilistic sampling technique allowed for a particular sampling bias. Specifically, those with more positive views on gamification might have been more likely to participate in the study, limiting the generalizability of the study's findings.

In the future, overcoming these sampling and methodological shortcomings should be a priority, as well as using theoretical frameworks such as Theory of Planned Behavior [61] or Technology Acceptance Model [62] for a more systematical approach. In order to gain a more in-depth insight into pre-service and in-service teachers' attitudes towards the use of gamification, qualitative methods such as interviews and focus groups could be used. In particular, we could target users who have used gamification systematically and for a longer period, for example, those who have gamified the learning process with a particular application over a school year. Due to recent concerns about whether behavioral intention to use certain technology in teaching translates to actual behavior [63], follow-up or longitudinal studies would be especially valuable. Even though this study compared pre-service and in-service teachers' views, this paper did not focus on comparing the detailed experiences of those who have already used gamification with the expectations and concerns of those who have not yet chosen this approach in their practice.

\section{Conclusion}

This paper presents the results of a questionnaire-based study on teachers' attitudes, experiences, familiarity, and intention of gamification use in education. This is the first study on gamification views that includes teachers from all educational levels and compares them with those from pre-service teachers. We used a comprehensive instrument to measure teachers' attitudes and developed a mediation model, thus 
advancing the descriptive and explorative nature of previous studies. Participants generally viewed gamification favorably, with students showing some more reservations, and were interested to use it and learn more about the subject. In their desire to motivate their students, teachers were open and accepting of new approaches but needed additional support to build upon their competencies to implement them, mainly in the form of additional knowledge and practical experience. Regular knowledge transfer from research into practice is thus highly desired to enable teachers to use innovative and effective pedagogical strategies in their classroom, as well as more research to understand the factors that affect their adoption. Attitudes have been shown to play an important role in planning the future use of gamification, which provides a basis for designing teacher trainings and support. Overall, there is clear terminology confusion in both professional and scientific communities, as gamification, game-based learning, serious, didactic, and educational games are often used as synonyms [6]. In the future, effort needs to be put into clearly defining and differentiating between the terms and designing research that ensures participants have the same understanding of crucial concepts.

\section{Acknowledgments}

The authors gratefully acknowledge the European Commission for funding the InnoRenew project (Grant Agreement \#739574) under the H2020 Widespread-2Teaming programme and the Republic of Slovenia (investment funding from the Republic of Slovenia and the European Regional Development Fund). Part of this work was conducted during the CLICKdesign project, which is supported under the umbrella of ERA-NET Cofund ForestValue. The authors would also like to thank Dean Lipovac for providing feedback on the manuscript and Liz Dickinson for language editing.

\section{$7 \quad$ Data availability statement}

Supplementary materials and the data underlying this article are available in Zenodo at https://doi.org/10.5281/zenodo.5493698 [49].

\section{$8 \quad$ References}

[1] Z. Ozcinar, V. G. Zakirova, R. A. Kurbanov, and A. M. Belyalova, "Analysis of the documents published in the web of science database on teachers' gamification method: A content analysis," Int. J. Emerg. Technol. Learn., vol. 14, no. 22, pp. 82-94, 2019. https:// doi.org/10.3991/ijet.v14i22.11741

[2] A. Manzano-León et al., "Between level up and game over: A systematic literature review of gamification in education,” Sustain., vol. 13, no. 4, pp. 1-14, 2021. https://doi.org/10.33 90/su13042247

[3] R. Scherer, F. Siddiq, and J. Tondeur, "The technology acceptance model (TAM): A metaanalytic structural equation modeling approach to explaining teachers' adoption of digital 
technology in education," Comput. Educ., vol. 128, no. 0317, pp. 13-35, 2019. https://doi. org/10.1016/j.compedu.2018.09.009

[4] A. Granić and N. Marangunić, "Technology acceptance model in educational context: A systematic literature review," Br. J. Educ. Technol., vol. 50, no. 5, pp. 2572-2593, 2019. https://doi.org/10.1111/bjet.12864

[5] A. I. Starčič and M. Lebeničnik, "Investigation of University Students' Perceptions of their Educators as Role Models and Designers of Digitalized Curricula," Hum. Technol., vol. 16, no. February, pp. 55-91, 2020. https://doi.org/10.17011/ht/urn.202002242163

[6] N. Sajinčič, A. Sandak, and A. Istenič Starčič, "Gamification in Education and Learning," 2019, pp. 993-1001.

[7] S. Deterding, D. Dixon, R. Khaled, and L. Nacke, "From game design elements to gamefulness: Defining 'gamification,"” 2011. https://doi.org/10.1145/2181037.2181040

[8] J. Majuri, J. Koivisto, and J. Hamari, "Gamification of education and learning: A review of empirical literature," CEUR Workshop Proc., vol. 2186, no. May, pp. 11-19, 2018.

[9] S. Subhash and E. A. Cudney, "Gamified learning in higher education: A systematic review of the literature," Comput. Human Behav., vol. 87, no. February, pp. 192-206, 2018. https://doi.org/10.1016/j.chb.2018.05.028

[10] E. D. Mekler, F. Brühlmann, K. Opwis, and A. N. Tuch, "Do points, levels and leaderboards harm intrinsic motivation? An empirical analysis of common gamification elements," ACM Int. Conf. Proceeding Ser., pp. 66-73, 2013. https://doi.org/10.1145/258 $\underline{3008.2583017}$

[11] R. Huang et al., "The impact of gamification in educational settings on student learning outcomes: a meta-analysis," Educ. Technol. Res. Dev., vol. 68, no. 4, pp. 1875-1901, Aug. 2020. https://doi.org/10.1007/s11423-020-09807-z

[12] M. Sailer and L. Homner, "The Gamification of Learning: a Meta-analysis," pp. 77-112, 2020. https://doi.org/10.1007/s10648-019-09498-w

[13] D. Dicheva, C. Dichev, G. Agre, and G. Angelova, "Gamification in education: A systematic mapping study," Educ. Technol. Soc., vol. 18, no. 3, pp. 75-88, 2015.

[14] I. Ajzen and M. Fishbein, "Attitudes and the Attitude-Behavior Relation: Reasoned and Automatic Processes," Eur. Rev. Soc. Psychol., vol. 11, no. 1, pp. 1-33, 2000. https://doi.o $\mathrm{rg} / 10.1080 / 14792779943000116$

[15] S. Breckler, "Empirical validation of affect, behavior, and cognition as distinct components of attitude. Journal of Personality and Social Psychology, 47, 1191-1205," J. Pers. Soc. Psychol., vol. 47, no. 6, pp. 1191-1205, 1984. https://doi.org/10.1037/00223514.47.6.1191

[16] I. Ajzen and N. G. Cote, "Attitudes and the prediction of behavior," in Attitudes and attitude change, W. D. Crano and R. Prislin, Eds. Psychology Press, 2008, pp. 289-311.

[17] J. R. Fiel, "Knowledge, Attitude, Barriers, Motivation, and Adaption of Blended Learning," SMCC High. Educ. Res. J., vol. 2, no. 1, pp. 178-197, 2020. https://doi.org/10. 18868/cte.02.060120.14

[18] A. Mustafina, "Teachers' Attitudes toward Technology Integration in a Kazakhstani Secondary School," Int. J. Res. Educ. Sci., vol. 2, no. 2, pp. 322-332, 2016. https://doi.org/ 10.21890/ijres.67928

[19] R. G. Gaboy, M. C. Mabalay, M. E. Mananghaya, M. G. M. Mercado, and B. M. Romblon, "Coping with the new norm: ICT-pedagogy integration awareness and competencies of TEI faculty," J. Res. Policy Pract. Teach. Teach. Educ., vol. 10, no. 2, pp. 49-62, 2020. https://doi.org/10.37134/jrpptte.vol10.2.4.2020 
[20] Z. Turan, Z. Avinc, K. Kara, and Y. Goktas, "Gamification and education: Achievements, cognitive loads, and views of students," Int. J. Emerg. Technol. Learn., vol. 11, no. 7, pp. 64-69, 2016. https://doi.org/10.3991/ijet.v11i07.5455

[21] H. Bicen and S. Kocakoyun, "Perceptions of students for gamification approach: Kahoot as a case study," Int. J. Emerg. Technol. Learn., vol. 13, no. 2, pp. 72-93, 2018. https://doi. org/10.3991/ijet.v13i02.7467

[22] C. Hursen and C. Bas, "Use of gamification applications in science education," Int. J. Emerg. Technol. Learn., vol. 14, no. 1, pp. 4-23, 2019. https://doi.org/10.3991/ijet.v14i01. $\underline{8894}$

[23] R. W. Mee Mee et al., "Role of gamification in classroom teaching: Pre-service teachers' view," Int. J. Eval. Res. Educ., vol. 9, no. 3, pp. 684-690, 2020. https://doi.org/10.11591/ij ere.v9i3.20622

[24] G. Ş. Altuner Çoban, E. Bozkurt, and A. Kan, "The development of an attitude scale for educational games: The study of validity and reliability," Turkish Stud. Sci., vol. 14, no. 3, pp. 287-302, 2019.

[25] P. Mozelius, W. Hernandez, J. Sällström, and A. Hellerstedt, "Teacher Attitudes Toward Game-based Learning in History Education," Int. J. Inf. Commun. Technol. Educ., vol. 6, no. 4, pp. 27-35, 2018.

[26] M. Martín-Del-Pozo, A. G. V. Muñoz-Repiso, and A. H. Martín, "Video games and collaborative learning in education? A scale for measuring in-service teachers' attitudes towards collaborative learning with video games," Informatics, vol. 6, no. 3, pp. 1-13, 2019. https://doi.org/10.3390/informatics6030030

[27] H. Mahat et al., "The Readiness of Geography Teacher Trainees in Gamification Approach,” Rev. Int. Geogr. Educ. Online, vol. 11, no. 3, pp. 720-734, 2021.

[28] H. Yaşar, M. Kıyıcı, and A. Karataş, "The views and adoption levels of primary school teachers on gamification, problems and possible solutions," Particip. Educ. Res., vol. 7, no. 3, pp. 265-279, 2020. https://doi.org/10.17275/per.20.46.7.3

[29] D. J. Fisher, J. Beedle, and S. E. Rouse, "Gamification: a Study of Business Teacher Educators' Knowledge of, Attitudes Toward, and Experiences With the Gamification of Activities in the Classroom," J. Res. Bus. Educ., vol. 56, no. 1, pp. 1-16, 2014.

[30] Z. Khlaif, "Teachers' Perceptions of Factors Affecting Their Adoption and Acceptance of Mobile Technology in K-12 Settings," Comput. Sch., vol. 35, no. 1, pp. 49-67, 2018. https://doi.org/10.1080/07380569.2018.1428001

[31] K. W. Lai and L. Smith, "Socio-demographic factors relating to perception and use of mobile technologies in tertiary teaching," Br. J. Educ. Technol., vol. 49, no. 3, pp. 492504, 2018. https://doi.org/10.1111/bjet.12544

[32] A. Başal and N. E. Kaynak, "Perceptions of pre-service English teachers towards the use of digital badges," Innov. Educ. Teach. Int., vol. 57, no. 2, pp. 148-162, Mar. 2020. https:// doi.org/10.1080/14703297.2019.1649172

[33] J. Martí-Parreño, D. Seguí-Mas, and E. Seguí-Mas, "Teachers' Attitude towards and Actual Use of Gamification," in Procedia - Social and Behavioral Sciences, 2016, vol. 228, no. July, pp. 682-688. https://doi.org/10.1016/j.sbspro.2016.07.104

[34] D. Alabbasi, "Exploring graduate students' perspectives towards using gamification techniques in online learning," Turkish Online J. Distance Educ., vol. 18, no. 3, pp. 180196, 2017. https://doi.org/10.17718/tojde.328951

[35] J. Martí-Parreño, A. Galbis-Córdova, and R. Currás-Pérez, "Teachers' beliefs about gamification and competencies development: A concept mapping approach," Innov. Educ. Teach. Int., vol. 58, no. 1, pp. 84-94, Jan. 2021. https://doi.org/10.1080/14703297.2019.16 $\underline{83464}$ 
[36] H. Uzunboylu, E. G. Galimova, R. A. Kurbanov, A. M. Belyalova, N. Deberdeeva, and M. Timofeeva, "The Views of the Teacher Candidates on the Use of Kahoot as A Gaming Tool," Int. J. Emerg. Technol. Learn., vol. 15, no. 23, pp. 158-168, 2020. https://doi.org/1 0.3991/ijet.v15i23.18811

[37] A. Sánchez-Mena and J. Martí-Parreño, "Drivers and barriers to adopting gamification: Teachers' perspectives," Electron. J. e-Learning, vol. 15, no. 5, pp. 434-443, 2017.

[38] E. Brooks et al., "What Prevents Teachers from Using Games and Gamification Tools in Nordic Schools?," in Interactivity, Game Creation, Design, Learning, and Innovation, 2019, pp. 472-484. https://doi.org/10.1007/978-3-030-06134-0_50

[39] Z. Luo, C. Brown, and B. O'Steen, “Factors contributing to teachers' acceptance intention of gamified learning tools in secondary schools: An exploratory study," Educ. Inf. Technol., no. 0123456789, 2021. https://doi.org/10.1007/s10639-021-10622-Z

[40] O. Nov and C. Ye, "Personality and technology acceptance: Personal innovativeness in IT, openness and resistance to change," Proc. Annu. Hawaii Int. Conf. Syst. Sci., no. October 2014, 2008. https://doi.org/10.1109/HICSS.2008.348

[41] P. Boyd, "Openness," in Encyclopedia of Personality and Individual Differences, V. Zeigler-Hill and T. K. Shackelford, Eds. Cham: Springer International Publishing, 2020, pp. 3333-3340. https://doi.org/10.1007/978-3-319-24612-3_1258

[42] F. Camadan, I. Reisoglu, Ö. F. Ursavas, and D. Mcilroy, "How teachers' personality affect on their behavioral intention to use tablet PC," Int. J. Inf. Learn. Technol., vol. 35, no. 1, pp. 12-28, 2018. https://doi.org/10.1108/IJILT-06-2017-0055

[43] J. Hamari and T. Nousiainen, "Why do teachers use game-based learning technologies? The role of individual and institutional ICT readiness," Proc. Annu. Hawaii Int. Conf. Syst. Sci., vol. 2015-March, pp. 682-691, 2015. https://doi.org/10.1109/HICSS.2015.88

[44] M. Denden, A. Tlili, F. Essalmi, and M. Jemni, "Does personality affect students' perceived preferences for game elements in gamified learning environments?," Proc. IEEE 18th Int. Conf. Adv. Learn. Technol. ICALT 2018, pp. 111-115, 2018. https://doi. org/10.1109/ICALT.2018.00033

[45] A. Tlili, M. Denden, F. Essalmi, M. Jemni, R. Huang, and T. W. Chang, "Personality effects on students' intrinsic motivation in a gamified learning environment," Proc. - IEEE 19th Int. Conf. Adv. Learn. Technol. ICALT 2019, vol. 2161-377X, no. Imi, pp. 100-102, 2019. https://doi.org/10.1109/ICALT.2019.00036

[46] H. Broekkamp and B. Van Hout-Wolters, "The gap between educational research and practice: A literature review, symposium, and questionnaire," Educ. Res. Eval., vol. 13, no. 3, pp. 203-220, 2007. https://doi.org/10.1080/13803610701626127

[47] Ö. F. Ursavaş, Y. Yalçın, and E. Bakır, "The effect of subjective norms on preservice and in-service teachers' behavioural intentions to use technology: A multigroup multimodel study," Br. J. Educ. Technol., vol. 50, no. 5, pp. 2501-2519, 2019. https://doi.org/10.1111/ bjet. 12834

[48] T. Teo, "Comparing pre-service and in-service teachers' acceptance of technology: Assessment of measurement invariance and latent mean differences," Comput. Educ., vol. 83, pp. 22-31, 2015. https://doi.org/10.1016/j.compedu.2014.11.015

[49] N. Sajinčič, A. Sandak, and A. Istenič, "Pre-service and In-service Teachers' Views on Gamification [Dataset \& Supplementary Materials]." pp. 1-9, 2021.

[50] K. Finstad, "Response interpolation and scale sensitivity: Evidence against 5-point scales," J. Usability Stud., vol. 5, no. 3, pp. 104-110, 2010.

[51] Statistical Office of Republic of Slovenia, "Opisi kategorij KLASIUS-P [Description of KLASIUS-P categories],” 2006. [Online]. Available: https://www.stat.si/Klasius/Docs/opi siKLASIUS-P.pdf [Accessed: 05-Nov-2019]. 
[52] E. M. Noraddin and N. T. Kian, “Academics' Attitudes Toward Using Digital Games for Learning \& Teaching in Malaysia," Malaysian Online J. Educ. Technol., vol. 2, no. 4, pp. $1-21,2014$.

[53] B. Weijters, H. Baumgartner, and N. Schillewaert, "Reversed item bias: An integrative model," Psychol. Methods, vol. 18, no. 3, pp. 320-334, 2013. https://doi.org/10.1037/a003 $\underline{2121}$

[54] N. Sajinčič, A. Sandak, and A. Istenič, "How do Slovenian educators feel about gamification? Interested to know more," in Educ. Self Dev., to be published.

[55] F. R. Lang, D. John, O. Lüdtke, J. Schupp, and G. G. Wagner, "Short assessment of the Big Five: Robust across survey methods except telephone interviewing," Behav. Res. Methods, vol. 43, no. 2, pp. 548-567, 2011. https://doi.org/10.3758/s13428-011-0066-Z

[56] Faculty of Social Sciences, “1KA.” Ljubljana, Slovenia, 2019.

[57] R Core Team, "R: A Language and environment for statistical computing," 2020.

[58] The jamovi project, "jamovi." 2021.

[59] K. J. Preacher and A. F. Hayes, "Asymptotic and resampling strategies for assessing and comparing indirect effects in multiple mediator models," Behav. Res. Methods, vol. 40, no. 3, pp. 879-891, 2008. https://doi.org/10.3758/BRM.40.3.879

[60] W. Haynes, "Bonferroni Correction," in Encyclopedia of Systems Biology, W. Dubitzky, O. Wolkenhauer, K. H. Cho, and H. Yokota, Eds. New York: Springer, 2013.

[61] I. Ajzen, "The theory of planned behavior," Organ. Behav. Hum. Decis. Process., vol. 50, no. 2, pp. 179-211, 1991. https://doi.org/10.1016/0749-5978(91)90020-T

[62] F. D. Davis, "Perceived usefulness, perceived ease of use, and user acceptance of information technology," MIS Q. Manag. Inf. Syst., vol. 13, no. 3, pp. 319-339, 1989. https://doi.org/10.2307/249008

[63] H. Liu, L. Wang, and M. J. Koehler, "Exploring the intention-behavior gap in the technology acceptance model: A mixed-methods study in the context of foreign-language teaching in China," Br. J. Educ. Technol., vol. 50, no. 5, pp. 2536-2556, 2019. https://doi. org/10.1111/bjet.12824

\section{Authors}

Nežka Sajinčič is an assistant researcher at InnoRenew $\mathrm{CoE}$ and a PhD student at the Faculty of Education, University of Primorska, Slovenia. Her main research interests are fostering learning through the use of educational technology and innovations.

Anna Sandak is the research group leader in Wood Modification at the InnoRenew $\mathrm{CoE}$ and an associate professor and research associate at the FAMNIT, University of Primorska, Slovenia. She has PhD in Wood Science and M.Sc. in Biology. Anna is a member of SISNIR, International Committee for NIR, International Research Group on Wood Protection, International Society for Plant Spectroscopy and Network of Early-Career Sustainable Scientist \& Engineers.

Andreja Istenič is professor in didactics at University of Primorska and University of Ljubljana, Slovenia. Her teaching and research interests include educational technology, teacher education, research evaluation, and particularly, interdisciplinary research. Andreja was editor of British Journal of Educational Technology and is member of editorial boards in Educational Technology Research and Development, International Journal of Emerging Technologies in Learning, Education and Self Development. Andreja has served as a visiting professor at the University of North Tex- 
as, Macquarie University Sydney, and Kazan Federal University. Andreja is author of the book Educational technology and construction of authentic learning environment (Email: andreja.istenic7@gmail.com).

Article submitted 2021-10-18. Resubmitted 2021-12-03. Final acceptance 2021-12-06. Final version published as submitted by the authors. 